\title{
Efficiency of Lichenicolous Fungi in Controlling Citrus Lichen Xanthoria parietina
}

\author{
*Fatma M. Abd-El wahab ; **Abdou M.M. Mahdy; **Gehad M. El-Habbaa; *Mohamoud A. Kamhawy \\ and $* *$ Khaled E. Eid \\ * Plant Pathology Institute, Agri. Res. Center (ARC), Giza, Egypt. \\ ** Plant Pathology Dept., Fac. Agric., Benha Univ., Egypt
}

\begin{abstract}
Lichenicolous fungi are not the same as the fungi that is the component of the lichen, which are known as lichenized fungi. This study was carried out to investigate the parasitic fungi which colonizing and attacking thalli and apothecia of citrus lichen Xanthoria parietina and the efficiency of using these fungi as lichenicolouss in its control. Several fungi were isolated from decayed thalli and apothecia and identified as Xanthoriicola physciae, Cladosporium sp., Alternaria sp., Drechslera sp., Botryodiplodia sp., Mucor sp., Aspergillus sp., Pestalotiopsis sp., Epicoccum nigrum, Fusarium sp., and Tellogalla oliveri. Xanthoriicola physciae was the most frequent and aggressive fungus in all collected decayed samples, anatomical investigation of decayed thalli and apothecia caused by Xanthoriicola physciae showed destruction and lytic symptoms on the tissue and formation of black mass production of hypha and conidiospores in the infected thalli and apothecia. All lichenicolous fungi were isolated and cultivated on PDA and Malt yeast extract media, parasitism of lichenicolous fungi was done by spore suspension of lichenicolous fungi to fresh healthy thalli and apothecia and the results of decay and damage were recorded.
\end{abstract}

Key words: Lichens, Citrus, Xanthoria parietina, Lichenicolous fungi, Xanthoriicola physciae

\section{Introduction}

Xanthoria parietina is a foliose ascomycete lichen belong to family Teloschistaceae. It has many common names such as common orange lichen, yellow scale, maritime sunburst lichen and shore lichen, it is a worldwide lichen and one of the most common lichens, and it is a widespread in Europe, Africa, Asia, Australia, and America on different phorophytes, it is also occurring on various substrates, e.g., fences, walls, roofs, and tombstones

( Lindblom 1997, Itten and Honneger, 2010). The photobionts symbiosis and associating with $X$. parietina are with green algae genus Trebouxia include T. arboricola and T. irregularis. (Ahmadjian, 1993), which occupy $7 \%$ of the volume of the thallus (Hale, 1977). In Egypt it is the most abundant lichen infecting fruit trees especially citrus (Koriem, 1990, 1994, 1999) also, it was first isolated and cultivated by Koriem (1991). Xanthoria parietina often associated with high level of nitrogen (Gaio-Oliveira et al., 2004), and it can be often found near farmland and around livestock ( Frati $\boldsymbol{e t}$ al., 2007), so it able to infect and attack with several fungi which terms lichenicolous fungi that are different from the dominant mycobiont in the thallus structure, the relationship of the lichenicolous fungi with the lichen thalli may either be parasitic, communalistic, mutualistic or saprophytic (Nash, 2008). Hawksworth (1982) reported that the term parasite for a lichenicolous fungus is only used if it causes visible damage to its host lichen or if cause complete destruction of the host, as the production of discolorations or as the development of gall-like malformations. Etayo and Berger (2009) recorded ten species of lichenicolous parasitic and saprotrophic fungi colonized a decaying community of lichen $X$. parietina and they recorded some saprotrophic taxa which not usually recorded on lichens as Cladosporium macrocarpum, Epicoccum nigrum. Also, another study by Fleischhacker (2011 new fungal species invading $X$. parietina thalli) were recorded and summarized into six species appear to be host-specific and facultative lichenicolous and fifteen species were obligate lichenicolous fungi with a broad host spectrum.

Xanthoria parietina is a very pollution-tolerant lichen, it can tolerate exposure to air contaminants and bisulphite ions with little or no any damaging effect (Silberstein, et al. 1996). Xanthoria parietina also is a very tolerant lichen to heavy metals contamination especially copper (Bačkor et $\boldsymbol{a l}$., 2003). This study aimed to find an effective method for controlling $X$. parietina by using lichenicolous parasitic fungi for control.

\section{Materials and Methods}

\section{1-Collection of lichenicolous fungi:}

Collection of lichenicolous fungi was during seasons of 2013-2017in citrus orchards located at seven different governorates i.e. Qalubyia, Sharkyia, Menofyia, Ismaelyia, Gharbyia, Beni-sweif, and Giza. The survey was achieved on citrus trees attacked with lichenicolous fungi which were visible to naked eye, the samples were collected and brought to the laboratories of Fruit and Woody Trees Diseases Research Department, Plant Pathology Institute, Agricultural Research Center, Giza, Egypt and kept at 
at room temperature for direct isolation, in addition to another morphological and anatomical identification studies.

\section{2- Isolation of lichenicolous fungi:}

Samples of infected and decayed lichens thalli and apothecia were examined with naked eye, hand lens , low and bower binocular then washed with tap water and cut into small pieces and sterilized with sodium hypochlorite 4\% (90 seconds) followed by sterile water (10 seconds) then the excess water was removed with filter paper, then the sterilized pieces were transferred to PDA or malt -yeast extract media and incubated at $27^{\circ}$ up to 4-6 days.

\section{Morphological identification of lichenicolous fungi:}

Identification of lichenicolous fungi was conducted based on the morphological characterization and symptoms of infection on diseased thalli and apothecia which were examined with naked eye, hand lens, low and bower binocular. Also, the colonies of isolated parasitic fungi were examined and identified according to the key of lichenicolous fungi identification by Hawksworth (1983) in addition to color photographs which used for lichenicolous fungi identification.

\section{Anatomical investigation of infected citrus lichen: 4.1. Microtome Sectioning Method:}

Pieces of healthy or infected thalli and apothecia of Xanthoria parietina with parasitic fungus Xanthoriicola physciae were washed in distilled water and dried between folds of sterilized paper towels and fixed in FAA solution $(500 \mathrm{~mL})$ which contains $250 \mathrm{~mL}$ ethanol $+25 \mathrm{~mL}$ glacial acetic acid + $50 \mathrm{~mL}$ formalin $+175 \mathrm{~mL}$ water for 24 hour , then dehydrated in ascending ethanol concentrations , paraffin wax was filtrated and then embedded as described by Johnson (1940), then the samples were sectioned using microtome, the sections were about $10-15 \mu$ and stained with safranin and fast green dyes, finally drops of canada balsam were added over the sections to cover them and left to dry, the prepared sections were examined using light microscopy and photographed.

Effect of different nutrients on the growth of lichenicolousic fungus Xanthoriicola physciae :

Three different cultures of solid media were used to test the best nutrient source on growth of Xanthoriicola physciae namely Potato Dextrose agar (PDA) which contains (Potato extract $200 \mathrm{~g}$, Agar $15.0 \mathrm{~g}$, Glucose $15.0 \mathrm{~g}$, Distilled water $1000 \mathrm{ml}$ ), Malt extract agar (MEA) which contains ( Malt extract $30.0 \mathrm{~g}$, Agar $15.0 \mathrm{~g}$, Glucose $15.0 \mathrm{~g}$, Peptone $5.0 \mathrm{~g}$, Distilled water $1000 \mathrm{ml}$ ) and Czapek's agar medium which contains ( Sodium nitrate $2.0 \mathrm{~g}$, Magnesium glycerophosphate $0.50 \mathrm{~g}$, Potassium chloride $0.50 \mathrm{~g}$
, Potassium sulphate 30.0 g Ferrous sulphate 0.01g, Sucrose $15.0 \mathrm{~g}$, Distilled water $1000 \mathrm{ml}$ ).

These media were prepared and poured into Petri plates then inoculated with $5 \mathrm{~mm}$ disc of $X$. physciae cut from actively growing culture on water agar medium and transferred to petri plates with three different media and incubated at $28 \pm 1^{\circ} \mathrm{C}$ for 7 days.

Observations were recorded when the fungus had completely covered the petri plates at any one of the media, the growth diameter, colony color, and sporulation were recorded.

\section{Biological control of lichen $X$. parietina:}

This study was carried out in vivo trial to investigate the efficiency of lichenicolous fungus $X$. physciae in controlling citrus lichen $X$. parietina.

\section{Preparation of $X$. physciae inoculum:}

The lichenicolous fungus $X$. physciae was grown on PDA medium, to test its lichenicolousic potentialities in vivo which appears as black decaying on the thalli and apothecia of lichen $X$. parietina. Petri dishes ( $9 \mathrm{~cm}$ in diameter), each contained $25 \mathrm{~mL}$ of PDA medium were inoculated with the tested lichenicolous then incubated at $28 \pm 1^{\circ} \mathrm{C}$ and the diameter of the colonies was measured for 12 days.

\section{Efficacy of tested lichenicolous fungus in reducing the lichen infection:}

Parasitism of lichenicolous fungus $X$. physciae was done by spraying its spore suspension on fresh thalli and apothecia of $X$. parietina which grown on citrus trees branches, (15 branches were used as replicates for treatment), then the results of infection on the lichen thalli and apothecia were recorded after 6,12 , and 18 months and the decaying percentage of treated colonies by the lichenicolousic fungus were estimated as the following formula:

Decaying percentage $\%=$

Number of decayed colonies after treatment

Number of healthy colonies before treatment

\section{Results}

\section{Morphological identification of lichenicolous fungi:}

Data in Table (1) and Figs. 1 and 2 illustrate that ten fungal genera attacked and killed the thalli and apothecia of citrus lichen Xanthoria parietina. The fungal genera differed in their symptoms of infection, it caused black, rose, and white decays of thalli and apothecia, also some genera as Mucor sp., Aspergillus sp. caused softening and lyses of lichen tissues especially if thalli hydrated with water. The identification of parasitic lichenicolous fungi which isolated from infected thalli and apothecia was based on their morphological characterization 
Xanthoriicola physciae , Cladosporium sp., Alternaria sp. , Drechslera sp. , Botryodiplodia sp., Mucor sp., Aspergillus sp. , Pestalotiopsis sp. , Epicoccum nigrum, Fusarium sp., and Tellogalla oliveri were identified. Lichenicolous fungus Xanthoriicola physciae was the most frequent and the most aggressive fungus among those lichenicolous fungi . X. physciae was identified according to descriptions of Hawksworth (1983) as follows: conidiophores immersed in the hymenium of the host, not forming sporodochia; conidiogenous cells phialidic; conidia, ellipsoid verruculose, not adhering in chains, 3. 5-6 $\mu \mathrm{m}$ diam, dark brown to black, parasitic on the apothecia and thalli of $X$. parietina and $X$. polycarpa where the infected apothecia turning sooty and black because of its mass production of hypha and conidiospores. The infected thalli also eventually being killed. In addition, there was only one fungus identified as Tellogalla oliveri caused galls and malformation on lichen thalli and apothecia

Table 1. The frequency and diagnosis of Lichenicolous fungi of Xanthoria parietina.

\begin{tabular}{llc}
\hline Lichenicolous fungus & Symptoms of infection & Number of collected Isolates \\
\hline Xanthoriicola physciae & Black decay on thalli and apothecia & 26 \\
Epicoccum nigrum & Purple brown patches on thalli & 4 \\
Fusarium sp. & Rose decay on thalli and apothecia & 3 \\
Cladosporium sp. & Black decay on thalli and apothecia & 7 \\
Alternaría sp. & Black decay on thalli and apothecia & 11 \\
Drechslera sp. & Black decay on thalli and apothecia & 3 \\
Botryodiplodia sp. & Black decay on thalli and apothecia & 6 \\
Mucor sp. & Softening and decaying of thalli & 2 \\
Pestalotiopsis sp. & White decay in the thalli & 1 \\
\hline
\end{tabular}
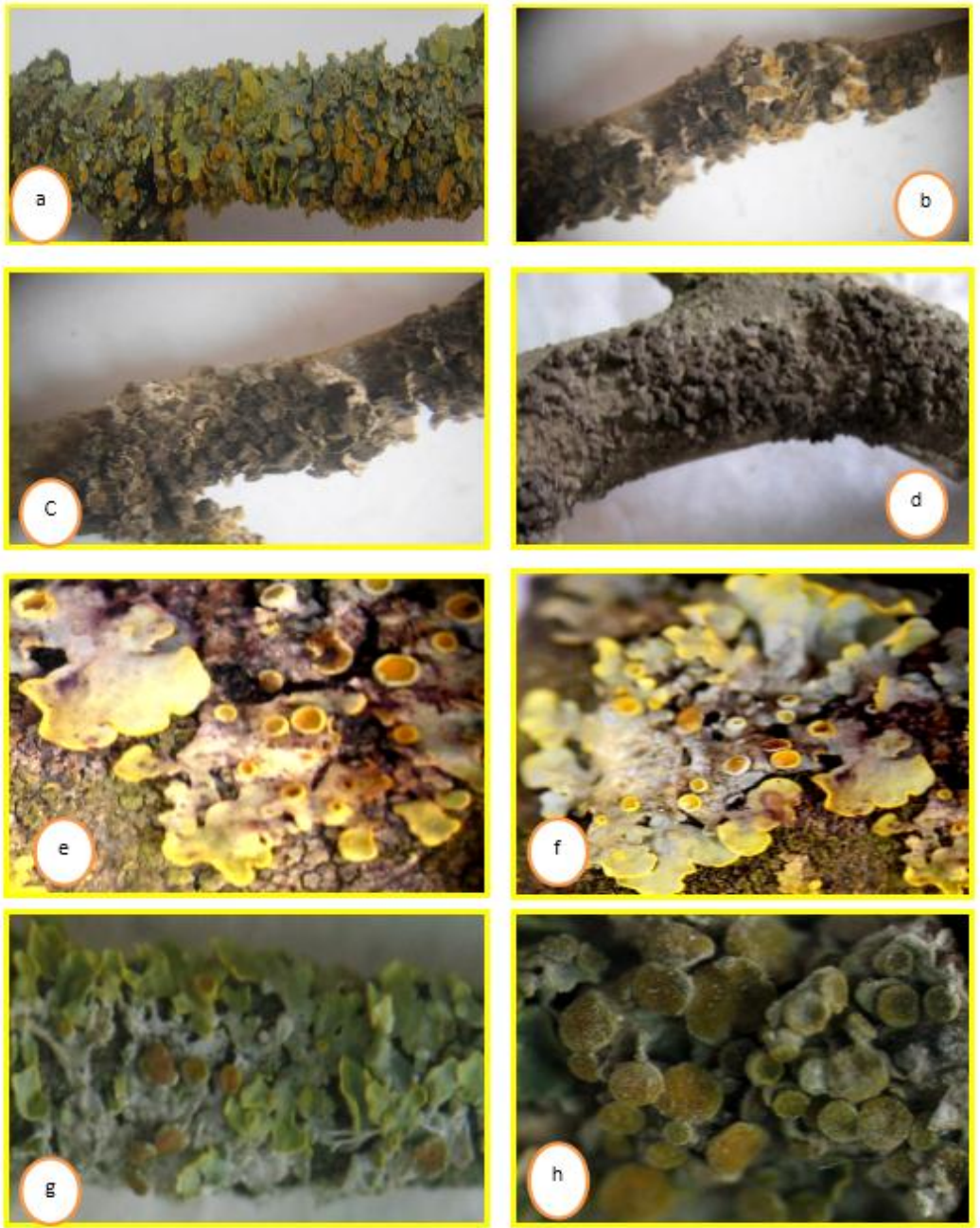

Fig.1infection symptoms with parasitic fungi of $X$. parietina.usingbowerbinuclar a-Xanthoriaparietina (healthy thalli and apothecia), b-c-Xanthoriicolaphysciae (12X) d-Drechslera sp. (12X), e-f- Epicoccumnigrum, (25X) g-h-Pestalotiopsissp(25X) 

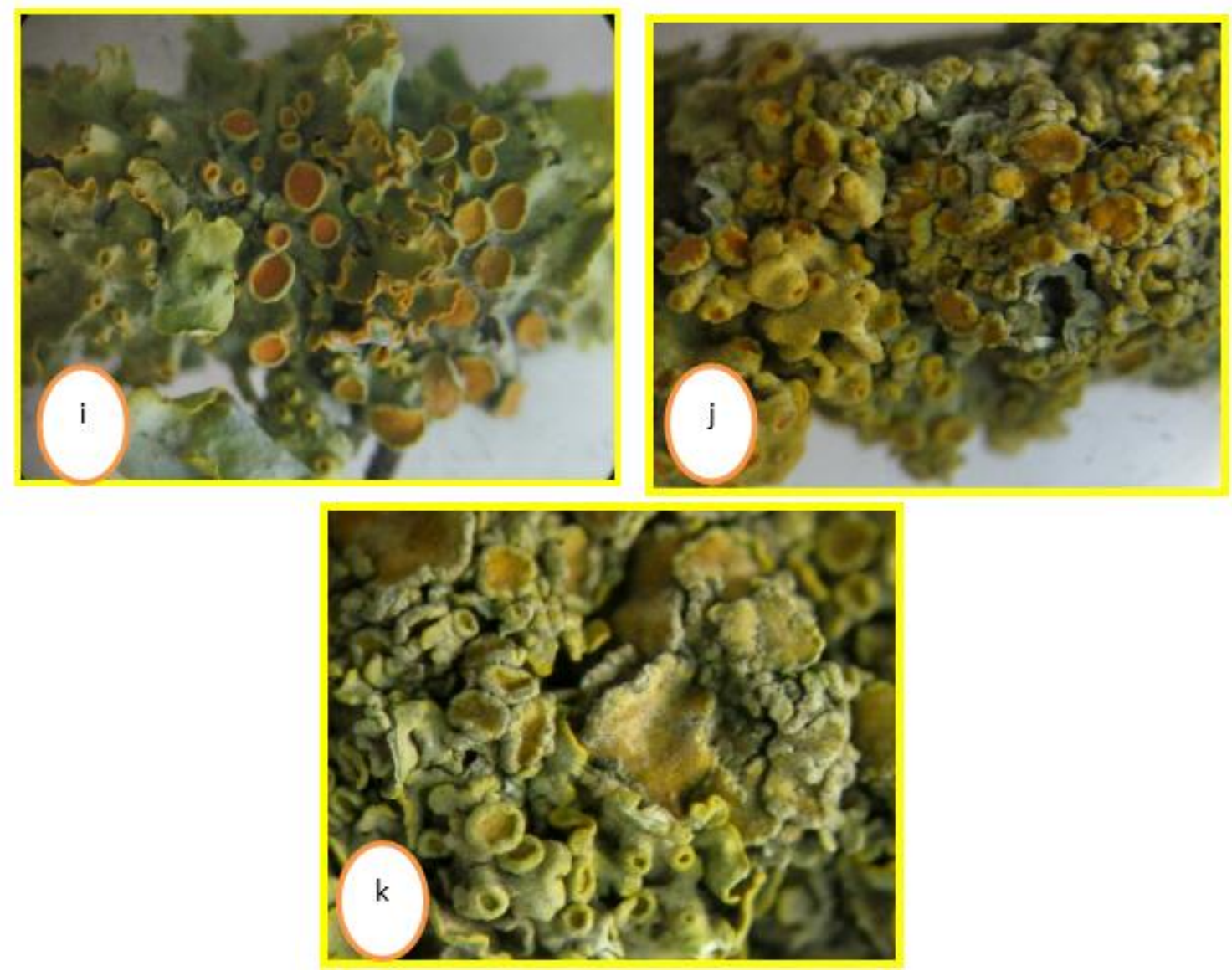

Fig (2): Malformation of Xanthoriaparietinathalli and a pothecia i- Xanthoriaparietina (healthy thalli and apothecia). b,c- Malformed thalli and apothecia caused by fungus Tellogallaoliveri(25X). 

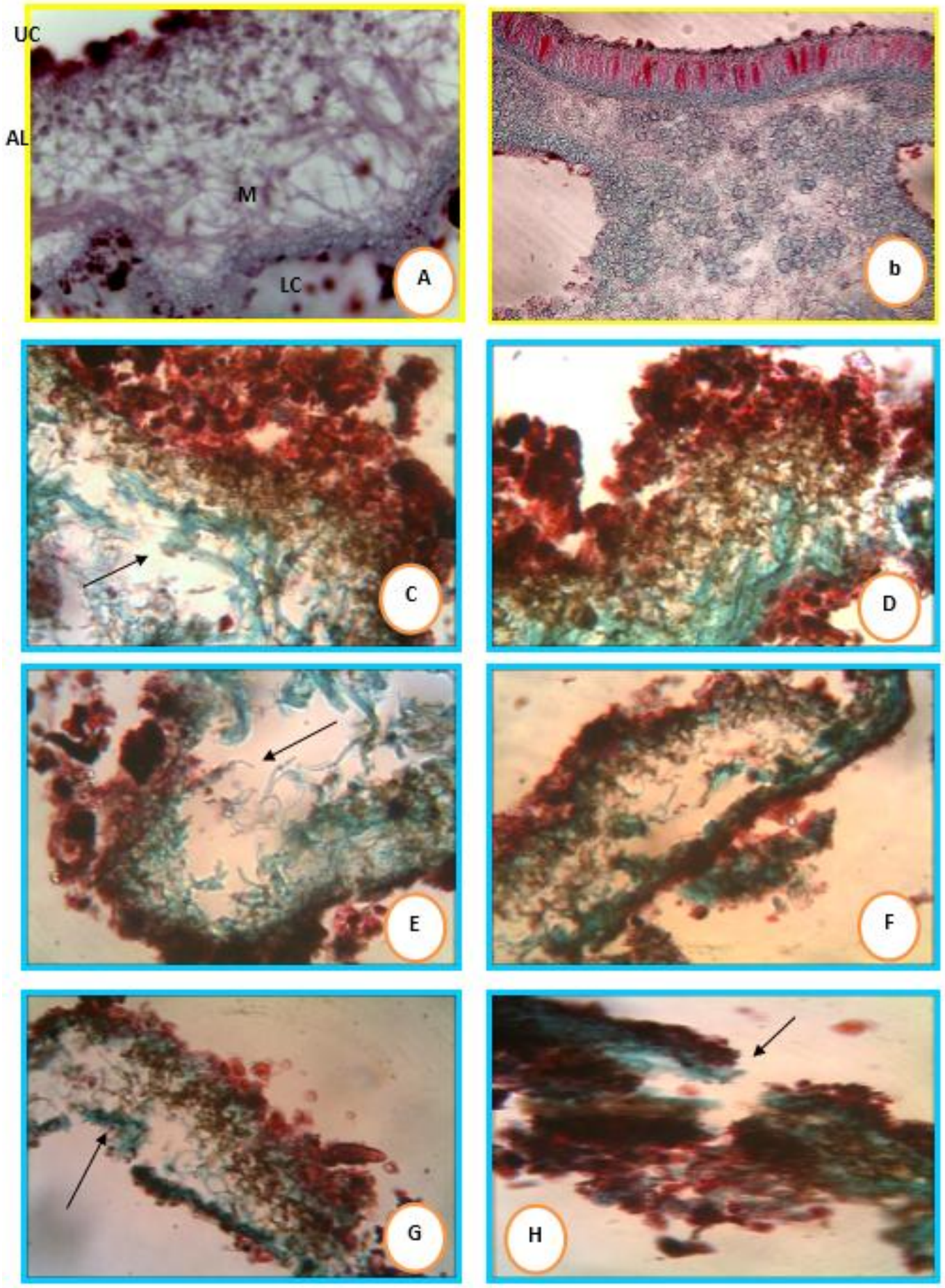

Fig 3. Anatomical investigation of infected thalli and apothecia of Xanthoriaparietinawithlichenicolous fungus $X$. physciae.

a- healthy thallus and b-healthy apothecium of $X$. parietina.c, $\mathrm{d}, \mathrm{e}, \mathrm{f}, \mathrm{g}$, destruction and lyses of infected lichen tissues and black mass of $X$. physciae hyphae and conidiosporesformed on the destroying tissues. h- Destroying apothecium of $X$. parietina caused by pathogenic fungus. UC, upper cortex, LC, lower cortex, AL, algal layer $\mathrm{r}$, $\mathrm{M}$, medulla. 
3- Effect of different nutrients on the growth of tested lichenicolous fungus $\mathrm{X}$. physciae:

Data presented in Table 2 and Fig 3 showed that, the maximum radial growth of $X$. physciae found on Malt yeast agar medium (MYM) which was reached about $2 \mathrm{~cm}$ for colonies diameter daily followed by potato dextrose agar medium (PDA) then Czapek's agar medium. Generally, the magnitude of effect was increased by increasing the days of incubation after inoculation on media.

Table 2. Effect of different nutrients on the growth of tested lichenicolous fungus X. physciae.

\begin{tabular}{llll}
\hline \multirow{2}{*}{ Days after inoculation } & \multicolumn{1}{c}{ MYM } & PDA & \multicolumn{1}{c}{ Czapek's agar } \\
\cline { 2 - 4 } & Mean of colonies diam./ cm & Mean of colonies diam./ cm & Mean of colonies diam./ cm \\
\hline Second day & 2.2 & 0.2 & 0.1 \\
Third day & 3.5 & 1.2 & 0.7 \\
Fourth day & 6.3 & 2.1 & 1.3 \\
Fifth day & 8.3 & 3.1 & 2.3 \\
Sixth day & 9 & 4.5 & 3.1 \\
\hline
\end{tabular}
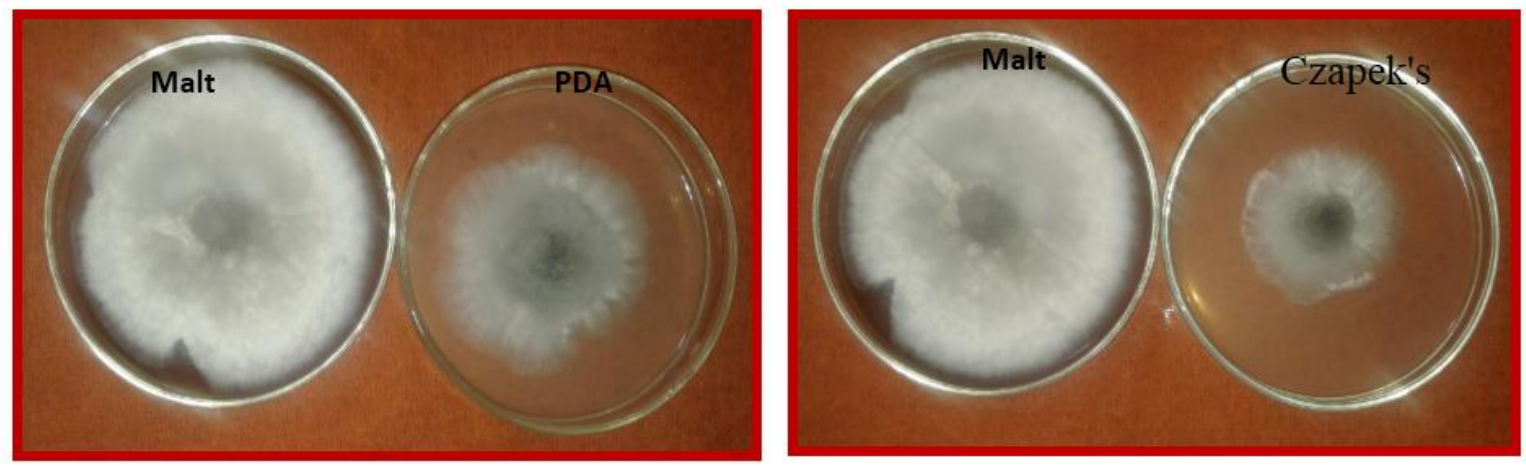

Fig (4). The most favorite solid mediaon radial growth of $X$. physciae

Efficiency of lichenicolous fungus $X$. physciae in controlling citrus lichen $X$. parietina :

The obtained data in Table 4 showed that $X$. physciae was the most effective lichenicolous fungus against $X$. parietina which caused citrus chlorosis, defoliation, inhibition of growth, cortex split, wounds beneath its growth by rhizinea.
As shown in Table $3 X$. physciae reduced the infection with lichen $\boldsymbol{X}$. parietina growing on citrus branches after treatment to healthy thalli and apothecia, reduction of infection reached about 57.1 to $100 \%$ of lichen thalli and apothecia on the infected branches.

Table 3. Efficiency of lichenicolous fungus $X$. physciae in controlling citrus lichen X. parietina.

\begin{tabular}{|c|c|c|c|c|c|c|}
\hline \multirow{3}{*}{$\begin{array}{l}\text { Number of thalli before } \\
\text { treatment per branch }\end{array}$} & \multicolumn{6}{|c|}{ Number of infected thalli after treatment per branch } \\
\hline & \multicolumn{2}{|c|}{6 months } & \multicolumn{2}{|c|}{12 months } & \multicolumn{2}{|c|}{18 months } \\
\hline & No. & Decaying\% & No. & Decaying\% & No. & Decaying\% \\
\hline 4 & 2 & 50 & 2 & 50 & 3 & 75 \\
\hline 6 & 4 & 66.6 & 4 & 66.6 & 4 & 66.6 \\
\hline 6 & 3 & 50 & 4 & 66.6 & 6 & 100 \\
\hline 3 & 1 & 33.3 & 2 & 66.6 & 3 & 100 \\
\hline 8 & 5 & 62.6 & 6 & 75 & 6 & 75 \\
\hline 7 & 3 & 42.8 & 3 & 42.8 & 4 & 57.1 \\
\hline 3 & 0 & 0 & 2 & 66.6 & 2 & 66.6 \\
\hline 4 & 1 & 25 & 2 & 50 & 4 & 100 \\
\hline 5 & 3 & 60 & 3 & 60 & 5 & 100 \\
\hline
\end{tabular}




\begin{tabular}{ccccccc}
\hline Table 3 cont. & 60 & 7 & 70 & 7 & 70 \\
\hline 10 & 6 & 62.5 & 6 & 75 & 6 & 75 \\
8 & 5 & 66.6 & 5 & 83.3 & 6 & 100 \\
6 & 4 & 44.4 & 6 & 66.6 & 8 & 88.8 \\
9 & 4 & 60 & 6 & 75 & 6 & 75 \\
8 & 5 & 66.6 & 4 & 66.6 & 4 & 75 \\
6 & 4 & & & & & \\
\hline
\end{tabular}
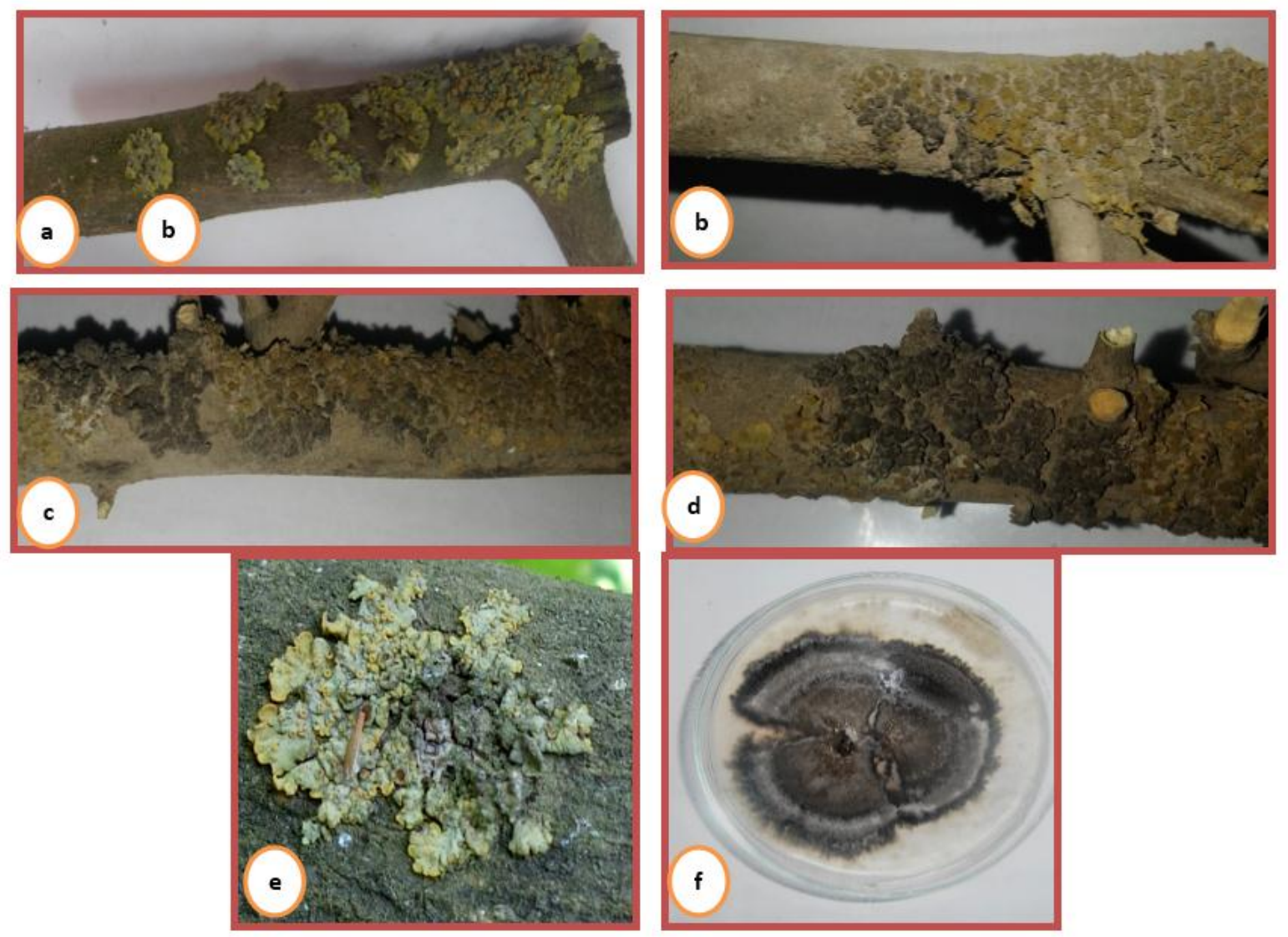

Fig 5: Illustrate thedecline andblack decaying on thethalli and apothecia caused bylichenicolous fungus $X$. physciae

a- healthy thalli and apothecia of X. parietina

b,c,d,e: Thedecaying on thethalli and apothecia caused bylichenicolousfungus $X$. physciae

f- Lichenicolous fungus $X$. physciae on PDA medium.

\section{Discussion}

Xanthoria parietina often associated with high level of nitrogen (Gaio-Oliveira, et al., 2004), and it can be often found near farmland and around livestock (Frati, et, al 2007). It has been known as a nitrophytic lichen, so nitrogen pollution caused by human activities in agriculture such as intensive livestock farming, nitrogen fertilization and cultivation of nitrogen-fixing crops constitutes it as a substrate and a host of diverse lichenicolous fungi.

Hawksworth (1982) reported that the term parasite for a lichenicolous fungus is only used if it causes visible damage to its host lichen either as local or complete destruction of the host, as the production of discolorations or as the development of gall-like malformations. Isolation of decayed thalli and apothecia of X. parietina observed different species of fungi identified as Xanthoriicola physciae, 
Cladosporium sp., Alternaria sp., Drechslera sp., Botryodiplodia sp., Mucor sp., Aspergillus sp., Pestalotiopsis sp., Epicoccum nigrum, Fusarium sp., that caused black, rose and white decays on the thalli and apothecia, while it was only one fungus caused malformations and galls on the thalli and apothecia and identified as Tellogalla oliveri. Some of these fungi were recorded by Etayo and Berger (2009), also another study by Fleischhacker (2011), new fungal species invading $X$. parietina has been recorded. Xanthoriicola physciae was the most frequented and aggressive fungus in all collected decayed samples, anatomy of infected thalli and apothecia caused by it showed destruction and lytic symptoms on the tissue and it formed black mass production of hypha and conidiospores in and on the surface of infected thalli and apothecia, this destruction and lytic symptoms on lichen tissues may be caused by the production of chitinase enzyme secreted by lichenicolous fungus. Rios et al., (2000) observed various infection mechanisms of lichenicolous fungi and they noted that some lichenicolous fungi were supposed to degrade parts of the host plectenchyma (fungal tissues). The effect of different nutrients on mycelial growth of lichenicolous fungus $X$. physciae showed that the maximum radial growth of $X$. physciae found on Malt yeast agar medium, while it was the minimum on Czapek's agar media, It is known that Malt extract is a good source of carbohydrates (George, et al., 2008), Yeast extract was also added as a source of amino acids and vitamins, especially inositol and thiamine (Vitamin B1).

$X$. physciae needs nutritional compounds like those of lichen tissues which contains large amounts of carbohydrates, in accordance with Smith and Berry (1974), Hamada and Miyagawa (1995); Huber et al., 1994; Molina, et al., 1997), fungal spores require organic carbon source during their germination to generate a three-dimensional structure, so malt and yeast extract of medium composition meet this requirement. Parasitism of lichenicolous fungus $X$. physciae was done by spore suspension on the healthy thalli and apothecia of $X$. parietina in vivo. Results of infection on the thalli and apothecia were recorded after 6, 12, and 18 months, the infection symptoms caused by $X$. physciae on thalli and apothecia observed after 6 months, a similar agreement on $X$. physciae as an aggressive parasite on thalli and apothecia of $X$. parietina but it cannot infected entire thalli easily compared with other parasites was investigated by Fleischhacker, (2011).

\section{References}

Ahmadjian, V. 1993. The Lichen Symbiosis. John Willey and Sons, Inc. New York. 248 pp.

Bačkor, M.; Fahselt, D.; Davidson, R and Wu, C.T. (2003). "Effects of copper on wild and tolerant strains of the lichen photobiont Trebouxia erici
(Chlorophyta) and possible tolerance mechanisms." Archives of Environmental Contamination and Toxicology 45: 159-67.

Etayo, J. and Berger, F. 2009. About a fastdeveloping community of lichenicolous deuteromycetes decaying Xanthoria parietina. Österreichische Zeitschrift für Pilzkunde18: 111115.

Fleischhacker, A. 2011. The lichenicolous fungi invading Xanthoria parietina. MSc. Thesis, der Karl-Franzens Faculty- Graz university- Germany. 1-96.

Frati, L., Santoni , S. , Nicolardi ,V. , Gaggi ,C. , Brunialti, G., Guttova ,A., Gaudino, S., Pati, A., Pirintsos ,S,A., Loppi S. 2007. Lichen biomonitoring of ammonia emission and nitrogen deposition around a pig stock farm. Environmental Pollution 146: 311\&ndsash; 6 .

Gaio- Oliveira, G.; Dahlman, L.; Palmqvist, K. and Máguas, C. 2004. Ammonium uptake in the nitrophytic lichen Xanthoria parietina and its effects on vitality and balance between symbionts. Lichenologist 36: 75-86.

George, E. F.; Hall, M. A. and Klerk, J. D. 2008. Plant Propagation by Tissue Culture. 3rd Edition. 1: 115-173.

Hale, M. E. Jr. 1974. The Biology of Lichens. 2ed. Edward Arnold (Pub) Ltd. London.

Hamada, N. and Miyagawa, H. 1995. Secondary metabolites from isolated lichen mycobionts cultured under different osmotic conditions. Lichenologist: 201-205.

Hawksworth, D. L. 1982. Notes on British lichenicolous fungi: IV. Notes R. bot. Gdn Edinb. 40: 129-151.

Hawksworth, D. L. 1983. A key to the lichenforming, parasitic, parasymbiotic and saprophytic fungi occurring on lichens in the British Isles. The Lichenologist 15: 1-44.

Huber, G.; Stocker-Wörgötter E. and Türk, R. 1994. Die kultivierung des MycobiontenVon Xanthoria parietina (L.) TH. FR. auf unterschieldlichen kulturmedien. Phyton (Horn). 33: $305-319$.

Itten, B. and Honegger, R. 2010. Population genetics in the homothallic lichen-forming ascomycete Xanthoria parietina. The Lichenologist, 42(06):751-761.

Johnson, D.A. 1940. Plant Micro technique. MC Grew- Hill Book Company, New york , P.523.

Koriem , A.M. 1990. Studies on the lichens of Egypt. I. Survey and identification of lichens Infection some fruit trees in Sharkia governorate.proc. of the sixth Congress of phytopathology, Vol.II.471-485, Cairo, Egypt.

Koriem , A.M. 1991. Studies on the lichens of Egypt. II. Isolation and cultivation of the mycobiont and phycobiont of lichen Xanthoria parietina infecting citrus trees in Sharkia governorate. $4^{\text {th }}$ Arab Congress of plant Protc., 55-64. 
Koriem , A.M. 1994. Studies on the lichens of Egypt III. Histopathological study of the lichens Xanthoria parietina and Diploicia canescens infecting mango trees in Sharkia governorate proc.of the seventh Congress of phytopathology, Vol.II.241-249, Cairo, Egypt.

Koriem, A.M. 1999. Studies on the lichens of Egypt. $\mathrm{V}$ - Light and electron microscopic study of the lichen Xanthoria parietina infecting fruit trees. proc. of the $8^{\text {th }}$ Nat.Conf. of pests \& Dis. Of Veg\& Fruits in Egypt, 281-292.

Lindblom, L. 1997. The genus Xanthoria (Fr.) Th.Fr. in North America. Journal of the Hattori Botanical Laboratory 83: 75-172.

Molina, M., Carmen, S. E.; Türk, R. and VICENTE, C. 1997. Axenic culture of the mycobiont of Xanthoria parietina in different nutritive media, effect of carbon source in spore germination. Endocytobiology and Cell Research. 12: 103-109.

Nash, T.H. 2008. Lichen Biology. Cambridge University Press, U.K.

Rios, M. de los, Ascaso, C. and Grube, M. 2000. Infection mechanisms of lichenicolous fungi. - In: The Fourth IAL Symposium, Progress and Problems in Lichenology at the Turn of the Millennium, Universitat de Barcelona, Barcelona: 102.

Silberstein, L.; Siegel, B.Z.; Sigel, S.M.; Mukhtar, A. and Galun, M. 1996. Comparative studies on Xanthoria parietina, a pollution-resistant lichen and Ramalina duriaei, a sensitive species. I. Effects of air pollution of physiologocal processes." Lichenologist 28(4): 355-65.

Smith, J. E. and Berry, D. R. 1974. An introduction to biochemistry of fungal development. Academic Press. London. New York. 326 pp.

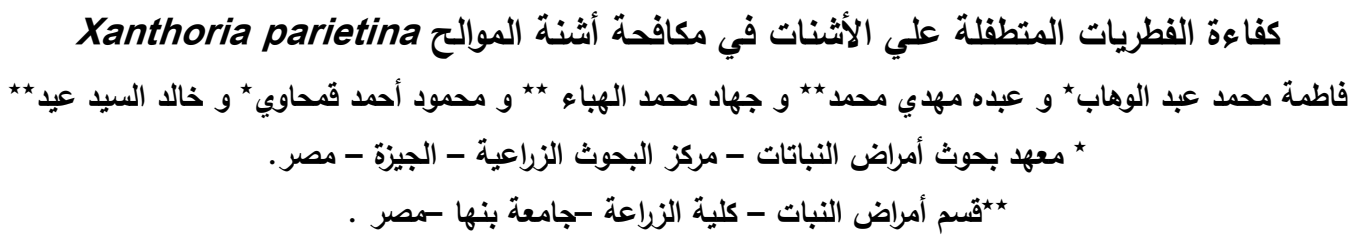

الفطريات المنطفلة علي الأثنات ليست كالفطريات الداخلة في تركيب الأشنات والتي تعرف بالفطريات المتأثنة وأجريت هذه الدراسة لتوضيح

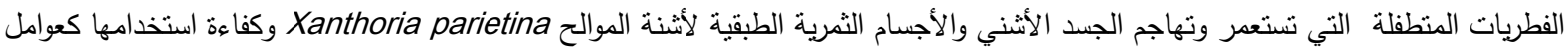

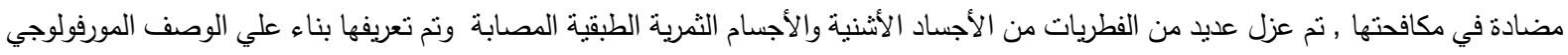

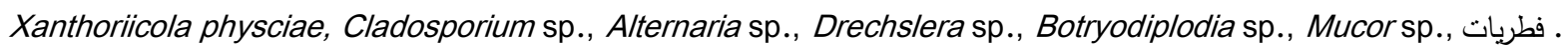
• تع تعريفها Aspergillus sp., Pestalotiopsis sp., Epicoccum nigrum, Fusarium sp. , and Tellogalla oliveri. فطر Xanthoriicola physciae كان أكثر الأنواع تكرار وضراوة في كل العينات المصابة التي تم تجميعها وبالفحص النتريحي للأجساد الأشنية

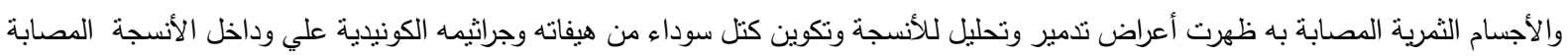

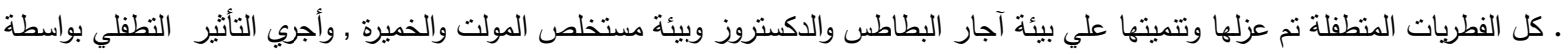

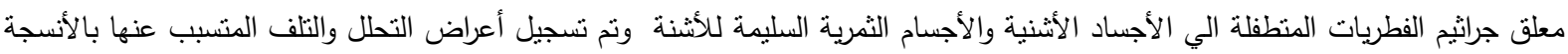

